\title{
LEDs for the Implementation of Advanced Hydrogenation Using Hydrogen Charge-State Control
}

\author{
Chee Mun Chong ${ }^{D},{ }^{1}$ Stuart Wenham, ${ }^{1}$ Jingjia Ji, ${ }^{1}$ Ly Mai, ${ }^{1}$ Sisi Wang, ${ }^{1}$ Brett Hallam, ${ }^{1}$ \\ and $\mathrm{Hua} \mathrm{Li}^{2}$ \\ ${ }^{1}$ School of Photovoltaic and Renewable Energy Engineering, University of New South Wales, Sydney, NSW, Australia \\ ${ }^{2}$ LONGi Lerri Solar, Xi'an, China \\ Correspondence should be addressed to Chee Mun Chong; cm.chong@unsw.edu.au
}

Received 7 November 2017; Revised 14 January 2018; Accepted 29 January 2018; Published 1 April 2018

Academic Editor: Chun-Sheng Jiang

Copyright (C) 2018 Chee Mun Chong et al. This is an open access article distributed under the Creative Commons Attribution License, which permits unrestricted use, distribution, and reproduction in any medium, provided the original work is properly cited.

\begin{abstract}
Light-induced degradation (LID) of p-type Cz solar cells has plagued the industry for many decades. However, in recent years, new techniques for solving this LID have been developed, with hydrogen passivation of the boron-oxygen defects appearing to be an important contributor to the solution. Advanced hydrogenation approaches involving the control of the charge state for the hydrogen atoms in silicon to enhance their diffusivity and reactivity are developed and evaluated in this work for commercial application using a prototype industrial tool in conjunction with solar cells manufactured on commercial production lines. This prototype tool, unlike the previous successful laser-based laboratory approaches, is based on the use of LEDs for controlling the charge state of the hydrogen atoms. The illumination from the LEDs is also used in this work to passivate process-induced defects and contamination from the respective production lines with significant improvements in both efficiency and stability. The results indicate that the low-cost LED-based industrial tool performs as well as the laser-based laboratory tool for implementing these advanced hydrogen passivation approaches.
\end{abstract}

\section{Introduction}

Hydrogen passivation of defects within silicon has been exploited and evaluated for several decades with perhaps more related published papers than most areas of semiconductor physics relating to semiconductor devices. Despite this, some discrepancies remain within published literature relating to areas of key importance such as the involvement of hydrogen in passivating defects such as B-O defects [1-4] and the diffusivity of hydrogen [5]. The theory behind charge states for interstitial hydrogen within silicon is well understood by some authors [6-8] as are the corresponding complications caused in interpreting data relating to the diffusivity of hydrogen and its reactivity $[9,10]$. Hydrogen diffusivity is reported to vary by 5 orders of magnitude, often confusing interpretations and corresponding conclusions in the literature. New insights and understanding in this important area are able to be gained for the first time through the innovative technology developed at UNSW Australia for control of the hydrogen charge state $[11,12]$ and its use in a range of ways for enhancing mobility and reactivity of hydrogen atoms [13]. This is particularly important for understanding the passivation of defects and recombination mechanisms within silicon solar cells that currently strongly dominate commercial markets.

This new technology from UNSW Australia makes possible for the first time the ability to control the charge state of hydrogen atoms within the silicon wafers, which in turn has facilitated drastic improvements in both the diffusivity (by as much as five orders of magnitude) and reactivity of the hydrogen atoms. Laboratory use of this innovative technology has demonstrated that by controlling the charge state, hydrogen atoms can be used to fix defects and recombination mechanisms within the silicon wafers that are not effectively passivated using conventional hydrogen passivation processes. This manipulation of hydrogen charge states 


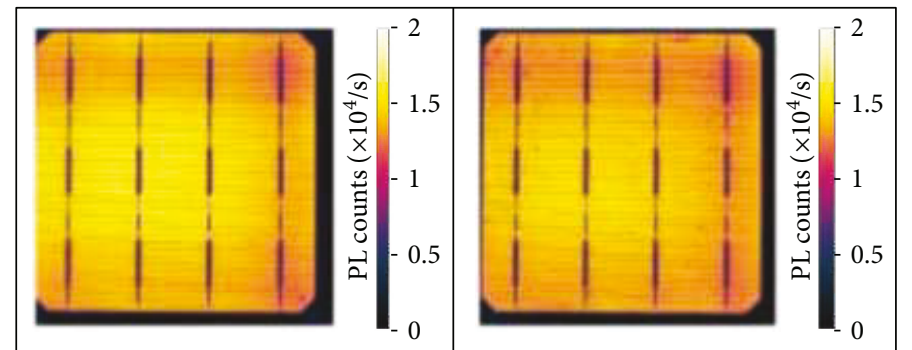

FIGURE 1: Photoluminescence images of two normal production solar cells (group 1) showing relatively uniform PL counts across the cell and only small reductions in the PL response in localised regions.

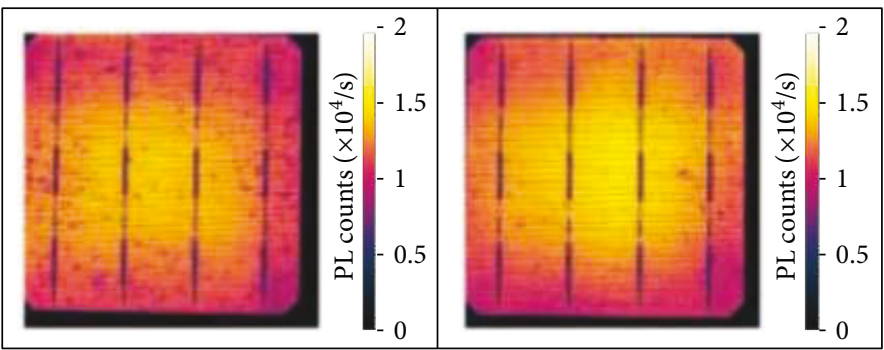

FIGURE 2: Photoluminescence images of two contaminated production solar cells (group 2) with many localised regions of heavily reduced PL response.

can transform the quality of even the worst commercial silicon wafers, into ones with quality equivalent to that of the very best wafers used by the semiconductor industry that can cost as much as one hundred times more [14-16]. This potentially enables the use of significantly lower-cost wafers in photovoltaic $(\mathrm{PV})$ manufacturing without significant performance loss and in fact has simultaneously demonstrated marked improvements in both efficiency and stability.

This technology has been developed and extensively demonstrated in the laboratory through the use of a laser illumination system [17-19] to control the carrier concentrations and hence the hydrogen charge state. As this new technology appears to have significant application in manufacturing, this work aims to study and demonstrate the compatibility of this technology to large area production solar cells using nonlaser illumination sources such as LED or metal halide lights. A new prototype production tool using an array of LED light sources combined with mirror-like reflectors was used to implement the control of the interstitial hydrogen charge states for large area screen-printed solar cells produced on commercial production lines. In particular, this prototype production tool enables the implementation of the hydrogenation technology to solve light-induced degradation (LID) in Czochralski (Cz) wafers and appears to also passivate many other forms of recombination due to contamination and crystallographic imperfections.

This new prototype production tool was specifically used to investigate the impact of the innovative hydrogenation technology on the performance and stability of silicon solar cells that are fabricated from p-type $\mathrm{Cz}$ on the production lines of an industry partner, Lerri Solar. These solar cells after treatment were stable and no longer susceptible to LID following the hydrogenation treatment.

\section{Experiment}

Commercial silicon solar cells from two production lines were obtained from Lerri Solar. These are $156 \mathrm{~cm} \times 156 \mathrm{~cm}$ screen-printed p-type monocrystalline silicon solar cells. One group of cells was obtained from the "normal" production line while a second group of cells were from a poorly performing, "contaminated" production line.

Being fabricated from the same $\mathrm{Cz}$ silicon wafers, both groups of cells are subject to LID. However, the cells from the contaminated production line also have localised degraded regions of low lifetime that appear to be as a result of contamination introduced during processing. Such contaminated regions are clearly evident in photoluminescence (PL) images [20] such as that shown in Figure 1 with their main impact being the increased ideality factor for the device suggesting that the contamination is creating significant junction recombination in these contaminated regions.

Cells from the normal production line represent our baseline control cells. Figure 2 shows the photoluminescence images [20] of these solar cells with PL counts as the unit. PL images have been deconvolved to negate the effects of photon smearing and improve clarity by the method of Payne et al. [21]. These cells are similar to any other p-type $\mathrm{Cz}$ production solar cells and are therefore susceptible to lightinduced degradation (LID) caused by the formation of recombination-active boron-oxygen defects. The aim is to use the new LED-based prototype production tool to implement the innovative hydrogenation technology involving the control of the hydrogen charge states on these cells to stabilise them and reduce or eliminate any subsequent LID.

Cells from the contaminated production line are similarly susceptible to LID, and their performance is also further 


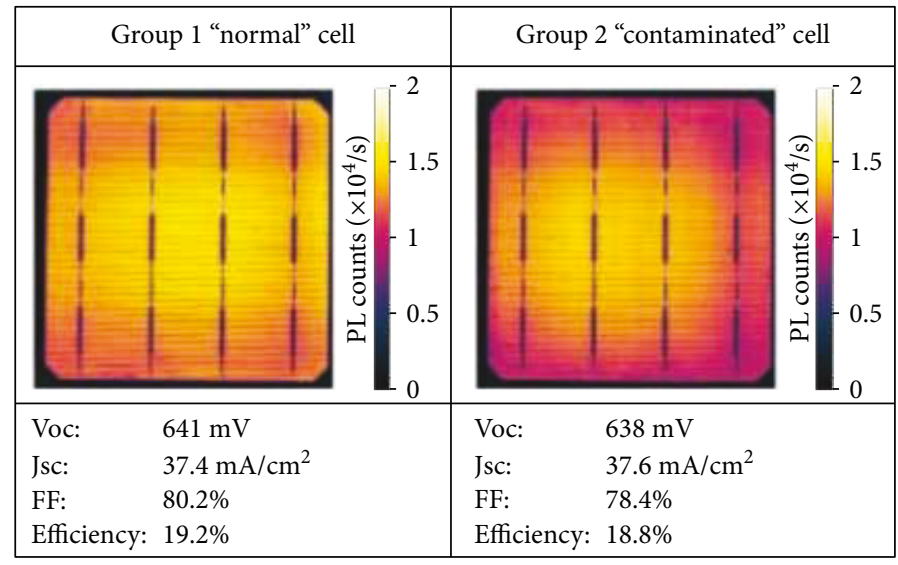

FIgURE 3: PL image and IV characteristics of a group 1 normal solar cell and a group 2 contaminated solar cell as received.

degraded by the contamination introduced during production. The aim is to use the hydrogenation technology to both passivate the damage caused by the contamination and to stabilise these cells to eliminate their LID. Figure 1 shows the photoluminescence images of these contaminated production solar cells. The localised contamination in these solar cells clearly shows up as dark spots in the open circuit photoluminescence images of Figure 1. Given that the PL response is proportional to carrier lifetime [20], these dark spots indicate areas of lower minority carrier lifetime throughout the solar cell.

Twelve solar cells from both these groups of production cells were put through the following process:

(1) PL images and IV characteristics of cells upon receipt from the industry partner were obtained.

(2) Half the cells were set aside (no treatment) while the other half of the cells were treated in the prototype hydrogenation tool.

(3) All the cells were subjected to a prolonged lightinduced degradation (LID) step performed at $35-40^{\circ} \mathrm{C}$ and $78 \mathrm{~mW} / \mathrm{cm}^{2}$ under halogen lamp illumination for up to 66 hours.

(4) PL images and IV characteristics of the cells following the prolonged LID step were obtained.

The prototype industrial hydrogenation tool is similar in design to many belt firing furnaces except that, in this case, the actual cell temperature is monitored and used as the measurement that determines the power delivered to the furnace. The primary heat source is the LED lights that operate predominantly at wavelengths of $490 \mathrm{~nm}$ and $560 \mathrm{~nm}$ (measured peak wavelengths) and at about $1.2 \mathrm{~W} / \mathrm{cm}^{2}$ but whereby the LED lights can be pulsed at any required frequency (or mark-space ratio) necessary to reduce the power delivered to the cells to keep the temperature at the desired level. These LEDs were chosen due to availability and being of a sufficiently short wavelength to generate electron-hole pairs. Since the carrier concentrations in the silicon are used for controlling the charge states for the hydrogen atoms, provided the off-time for the LED lights is significantly less than the minority carrier lifetimes in the wafer, the charge-state control for the hydrogen is not adversely affected by the pulsing. Lenses were used to ensure uniform illumination of the entire solar cell at an intensity of around 12 suns equivalent in relation to the density of photons available to generate electron-hole pairs within the solar cell.

The duration of the hydrogen passivation process is dependent upon the length of the furnace and the corresponding belt speed. For the present work, the duration of the passivation process was about 240 seconds, but with similar results achieved with much shorter times.

The cell PL images were measured using the lab tool R1 developed by BT Imaging. The open circuit voltage (Voc), short circuit current (Jsc), fill factor (FF), and cell efficiency were measured by a h.a.I.m. IV tester (AM 1.5, one sun, $25^{\circ} \mathrm{C}$ ).

\section{Results and Discussion}

The electrical properties of the solar cells are outlined in Figure 3, showing that group 1 normal cells perform better than group 2 contaminated cells, primarily due to higher fill factors.

The PL image of the group 2 contaminated solar cell shows dark spots across the cell, particularly around the edges of the cell. These represent locally defective areas that are most likely caused by contamination during processing. Such dark spots are not present in group 1 normal solar cells, and the PL images of group 1 normal solar cells are generally uniformly brighter by comparison. These cells have few regions with slightly reduced PL response, indicating only a low level of contamination.

Cells from group 1 and group 2 are light soaked for 48 hours to check their susceptibility to light-induced degradation. These cells showed a decrease in their performance, and the corresponding electrical properties are outlined in Figure 4.

The performance drops by $0.2-0.3 \%$ absolute in the solar cells after the 48-hour light soaking. This is most likely 


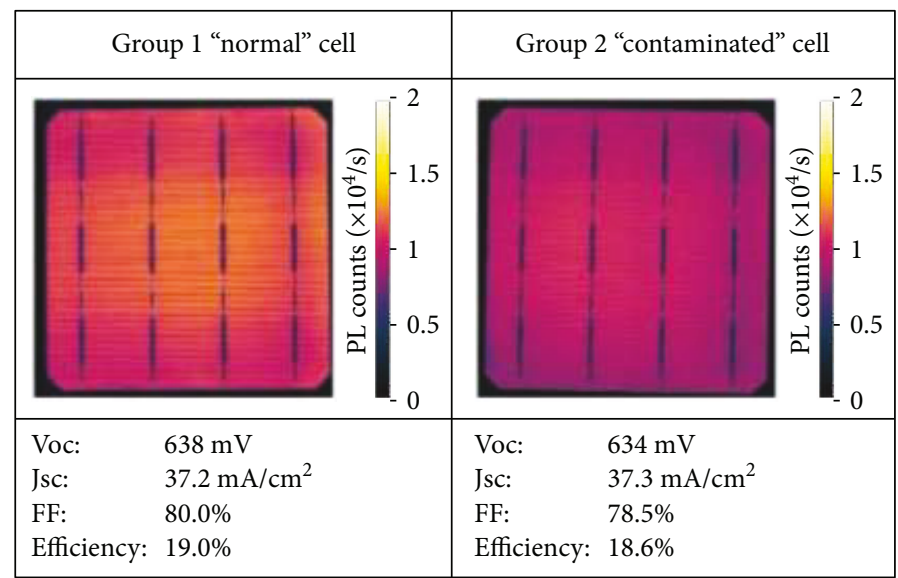

FIGURE 4: PL image and IV characteristics of a group 1 normal cell and group 2 contaminated cell solar cell after light soaking for 48 hours.

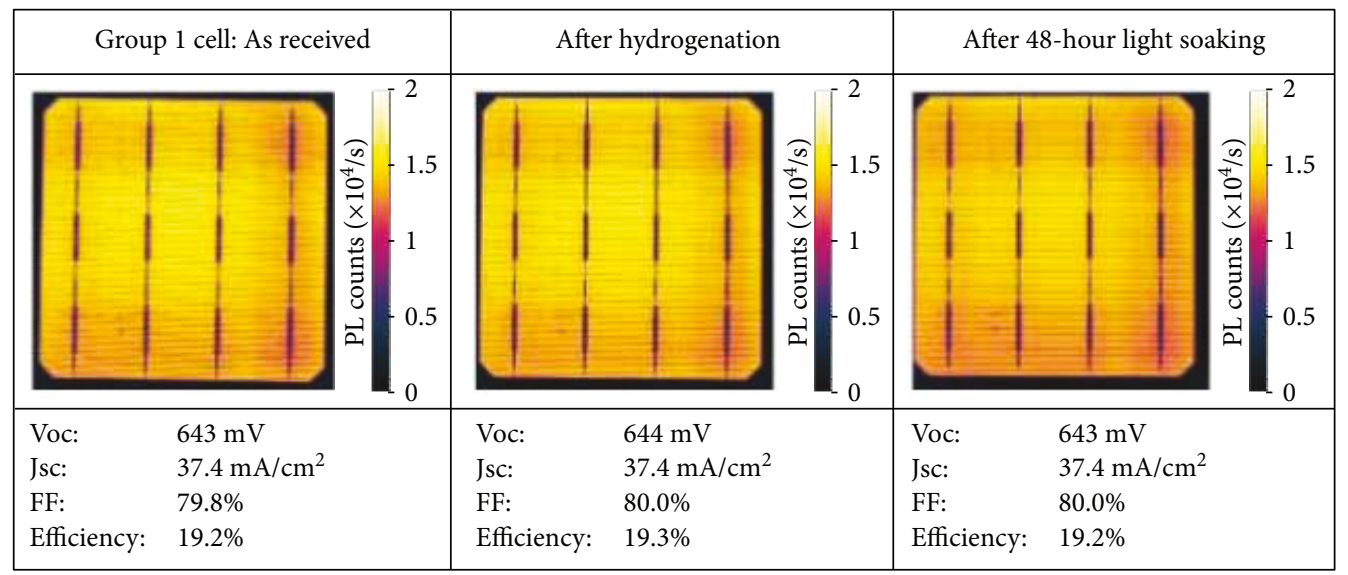

Figure 5: Performance of a group 1 normal cell after hydrogenation and then light soaking showing stable lifetimes after light soaking.

caused by the formation of B-O defects in the solar cells under illumination, a common degradation mechanism in p-type $\mathrm{Cz}$ silicon $[11,22]$. During light soaking, boron and oxygen in the solar cell are believed to bond together to form recombination-active $\mathrm{B}-\mathrm{O}$ defects, which then degrade the performance of the solar cells [23]. The formation of $\mathrm{B}-\mathrm{O}$ defects reduces carrier lifetime, which can significantly reduce the Voc. This reduction in lifetime also causes a slight reduction in the Jsc. Due to the injection-level dependence of the recombination caused by $\mathrm{B}-\mathrm{O}$ defects, a reduction in $\mathrm{FF}$ also occurs [18]. This lifetime degradation typically takes 24-48 hours at room temperature to take place. However, if the samples are light soaked for too long at these low temperatures, hydrogen can slowly passivate the B-O defects [24], therefore increasing the lifetime of the wafers, leading to a recovery in performance.

The UNSW hydrogenation technology is then applied to solar cells from both group 1 and group 2, and these cells were then light soaked for 48 hours. This gives a good indication of the impact of the hydrogenation technology on the performance and stability of these solar cells. The electrical properties of these cells are recorded in Figure 5 (group 1) and Figure 6 (group 2), respectively. This increased stability is due to the hydrogen passivation of the B-O defects, which protects against subsequent degradation. This results in stable electrical parameters after light soaking.

The performance of the solar cell improved marginally after undergoing hydrogenation. Most importantly, the solar cell was stable and did not degrade following exposure to light for 48 hours. These cells appear to be no longer susceptible to LID.

The performance of the group 2 contaminated cell improved by about $0.2-0.3 \%$ absolute following hydrogenation. This improvement in electrical performance is most likely due to the passivation of the defects in the solar cell caused by contamination introduced in the cell during production. The localised spots of high recombination evident in the PL images of Figure 1 are not nearly as prominent following the passivation treatment, suggesting that the passivation was having its greatest beneficial impact in these high recombination areas. Although the actual cause of the contamination is not as yet known, the fact that it affects every cell from the affected production line during device fabrication has made it relatively simple to use in-line PL monitoring throughout the line to ascertain the point at which the contamination is occurring. 


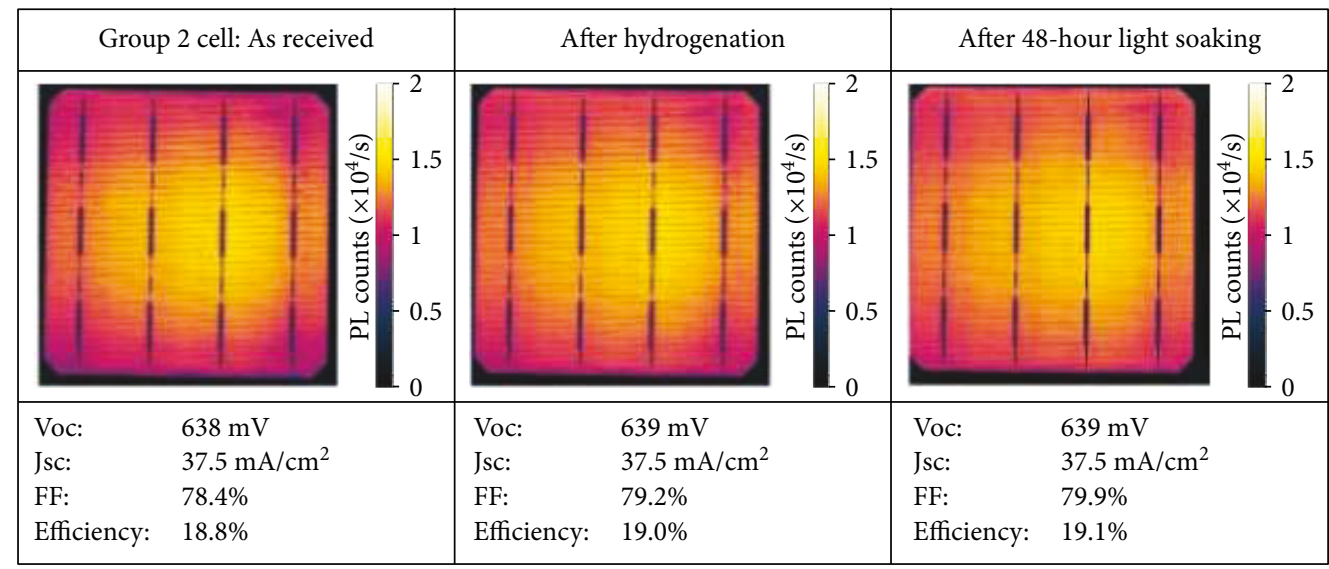

FIgURE 6: Performance of a group 2 contaminated cell after hydrogenation showing stable lifetimes after light soaking.

After light soaking, the passivated solar cell did not degrade, thus demonstrating that the cell is stable and not susceptible to LID. Interestingly, the performance of the solar cell actually increased slightly during light soaking. One possible reason for this is that only some of the defects caused by contamination were passivated during the hydrogenation process, with the remainder continuing to be passivated under the conditions imposed by the light soaking conditions. During the light soaking process which was conducted at slightly elevated temperatures, it is possible that defects caused by contamination near the junction region continue to be passivated and rendered inactive. As a result, the performance of the solar cell improved following light soaking. This suggests that the hydrogenation process needs to be further optimised so as to better passivate the defects caused by contamination introduced during production. In the same way, it is expected that the hydrogenation process is also able to passivate defects in solar cells arising from the use of lower cost, more highly defected silicon wafers, potentially enabling such wafers to lower costs while avoiding significant performance loss.

Interestingly, following hydrogenation and light soaking, the performance levels of the solar cells from group 1 are very similar to the performance of solar cells from group 2, with all appearing to be stable against future LID. This shows that for the latter, the hydrogenation process has passivated both the defects caused by contamination as well as the B-O defects upon exposure to light. Cells from this work from both groups are currently being encapsulated into panels so as to confirm the stability of the solar panels and monitor their performance in the field.

\section{Conclusions}

Hydrogen passivation of defects and recombination mechanisms within silicon wafers have been demonstrated in the laboratory. Following this treatment, solar cells demonstrated significant improvements in both efficiency and stability. A new prototype industrial tool for the implementation of this technology has been developed using LED lights. Large-area screen-printed p-type $\mathrm{Cz}$ silicon production solar cells treated in this prototype industrial tool showed a decrease in the degradation caused by contamination. Following light soaking, performance of these large area production solar cells was stable and did not decrease, indicating that the hydrogenation technology implemented with the LED lights has solved light-induced degradation in these p-type $\mathrm{Cz}$ silicon solar cells. Interestingly, following hydrogenation and light soaking, the performance levels of the contaminated solar cells are very similar to the performance levels of the normal solar cells indicating that the hydrogenation process implemented in the LED-based prototype industrial tool has passivated both the defects caused by contamination as well as the boron-oxygen defects upon exposure to light.

\section{Disclosure}

The views expressed herein are not necessarily the views of the Australian government, and the Australian government does not accept responsibility for any information or advice contained herein.

\section{Conflicts of Interest}

The authors declare that there is no conflict of interest regarding the publication of this paper.

\section{Acknowledgments}

This program has been supported by the Australian government through the Australian Research Council (ARC) and the Australian Renewable Energy Agency (ARENA). The authors would like to thank the UK Institution of Engineering and Technology (IET) for their funding support for this work through the A.F. Harvey Engineering Prize.

\section{References}

[1] K. Munzer, "Hydrogenated silicon nitride for regeneration of light induced degradation," in Proceedings of the 24th European Photovoltaic Solar Energy Conference 2009, pp. 1558-1561, Hamburg, 2009.

[2] S. Wilking, C. Beckh, S. Ebert, A. Herguth, and G. Hahn, "Influence of bound hydrogen states on BO-regeneration 
kinetics and consequences for high-speed regeneration processes," Solar Energy Materials and Solar Cells, vol. 131, pp. 2-8, 2014.

[3] D. Walter, B. Lim, K. Bothe, V. Voronkov, R. Falster, and J. Schmidt, "Effect of rapid thermal annealing on recombination centres in boron-doped Czochralski-grown silicon," Applied Physics Letters, vol. 104, no. 4, article 042111, 2014.

[4] N. Nampalli, B. Hallam, C. Chan, M. Abbott, and S. Wenham, "Evidence for the role of hydrogen in the stabilization of minority carrier lifetime in boron-doped Czochralski silicon," Applied Physics Letters, vol. 106, no. 17, article 173501, 2015.

[5] B. Sopori, Y. Zhang, and N. Ravindra, "Silicon device processing in $\mathrm{H}$-ambients: $\mathrm{H}$-diffusion mechanisms and influence on electronic properties," Journal of Electronic Materials, vol. 30, no. 12, pp. 1616-1627, 2001.

[6] C. Herring, N. M. Johnson, and C. G. Van de Walle, "Energy levels of isolated interstitial hydrogen in silicon," Physical Review B, vol. 64, no. 12, article 125209, 2001.

[7] N. Johnson and C. Herring, "Diffusion of negatively charged hydrogen in silicon," Physical Review B, vol. 46, no. 23, pp. 15554-15557, 1992.

[8] C. Seager and R. Anderson, "Two-step debonding of hydrogen from boron acceptors in silicon," Applied Physics Letters, vol. 59, no. 5, pp. 585-587, 1991.

[9] D. Mathiot, "Modeling of hydrogen diffusion in $n$ - and $p$-type silicon," Physical Review B, vol. 40, no. 8, pp. 5867-5870, 1989.

[10] R. Job, W. Fahrner, N. Kazuchits, and A. Ulyashin, "A twostep low-temperature process for a $\mathrm{P}-\mathrm{N}$ junction formation due to hydrogen enhanced thermal donor formation in P-type Czochralski Silicon," MRS Proceedings, vol. 513, no. 1, p. 337, 1998.

[11] B. J. Hallam, P. G. Hamer, S. R. Wenham et al., "Advanced bulk defect passivation for silicon solar cells," IEEE Journal of Photovoltaics, vol. 4, no. 1, pp. 88-95, 2014.

[12] P. Hamer, B. Hallam, S. Wenham, and M. Abbott, "Manipulation of hydrogen charge states for passivation of P-type wafers in photovoltaics," IEEE Journal of Photovoltaics, vol. 4, no. 5, pp. 1252-1260, 2014.

[13] S. Wenham, S. Wenham, P. Hamer et al., "Advanced hydrogenation of silicon solar cells, 2013," 2014, United States Patent 2015/0111333 A1.

[14] S. Wang, A. Wenham, P. Hamer et al., "Stability of hydrogen passivated UMG silicon with implied open circuit voltages over $700 \mathrm{mV}$," in 2015 IEEE 42nd Photovoltaic Specialist Conference (PVSC), New Orleans, LA, USA, 2015.

[15] J. Kraiem, B. Drevet, F. Cocco et al., "High performance solar cells made from 100\% UMG silicon obtained via the PHOTOSIL process," in 2010 35th IEEE Photovoltaic Specialists Conference, pp. 001427-001431, Honolulu, HI, USA, 2010.

[16] G. del Coso, C. del Canizo, and W. C. Sinke, "The impact of silicon feedstock on the PV module cost," Solar Energy Materials and Solar Cells, vol. 94, no. 2, pp. 345-349, 2010.

[17] P. Hamer, S. Wang, B. Hallam et al., "Laser illumination for manipulation of hydrogen charge states in silicon solar cells," Physica Status Solidi (RRL) - Rapid Research Letters, vol. 9, no. 2, pp. 111-114, 2015.

[18] B. Hallam, P. Hamer, S. Wang et al., "Advanced hydrogenation of dislocation clusters and boron-oxygen defects in silicon solar cells," Energy Procedia, vol. 77, pp. 799-809, 2015.
[19] L. Song, A. Wenham, S. Wang et al., "Laser enhanced hydrogen passivation of silicon wafers," International Journal of Photoenergy, vol. 2015, Article ID 193892, 13 pages, 2015.

[20] T. Trupke, R. Bardos, M. Schubert, and W. Warta, "Photoluminescence imaging of silicon wafers," Applied Physics Letters, vol. 89, no. 4, article 044107, 2006.

[21] D. N. R. Payne, M. K. Juhl, M. E. Pollard, A. Teal, and D. M. Bagnall, "Evaluating the accuracy of point spread function deconvolutions applied to luminescence images," in 2016 IEEE 43rd Photovoltaic Specialists Conference (PVSC), Portland, OR, USA, 2016.

[22] C. Sun, F. E. Rougieux, and D. Macdonald, "A unified approach to modelling the charge state of monatomic hydrogen and other defects in crystalline silicon," Journal of Applied Physics, vol. 117, no. 4, article 045702, 2015.

[23] J. H. Brett, E. C. Catherine, C. Ran et al., "Rapid mitigation of carrier-induced degradation in commercial silicon solar cells," Japanese Journal of Applied Physics, vol. 56, no. 8S2, article 08MB13, 2017.

[24] H. Brett, B. Jose, P. David et al., "Modelling the long-term behaviour of boron-oxygen defect passivation in the field using typical meteorological year data (TMY2)," in 32nd European Photovoltaic Solar Energy Conference and Exhibition, pp. 555-559, Munich, Germany, 2016. 

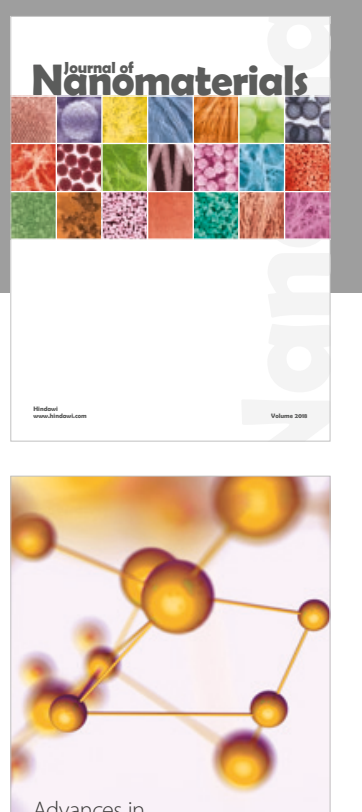

Physical Chemistry
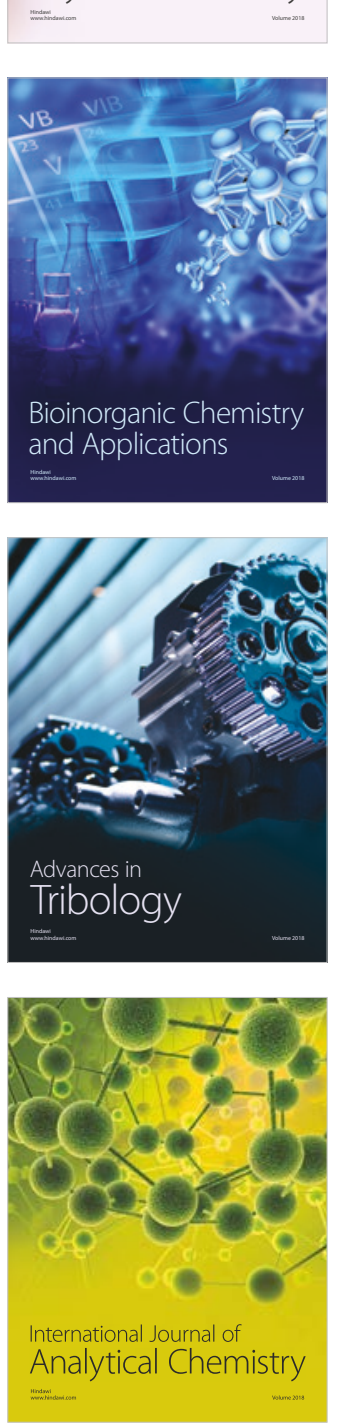

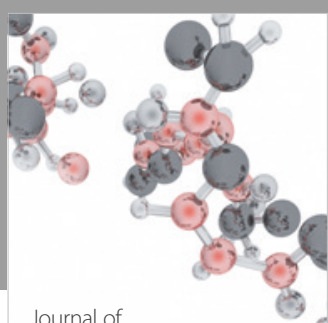

Analytical Methods

in Chemistry

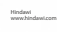

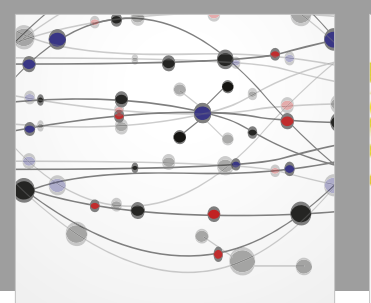

The Scientific World Journal

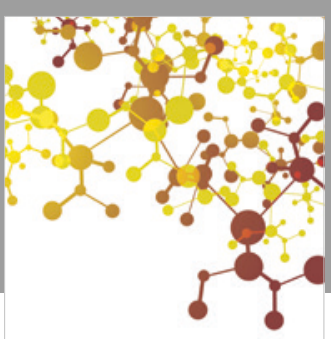

Journal of

Applied Chemistry
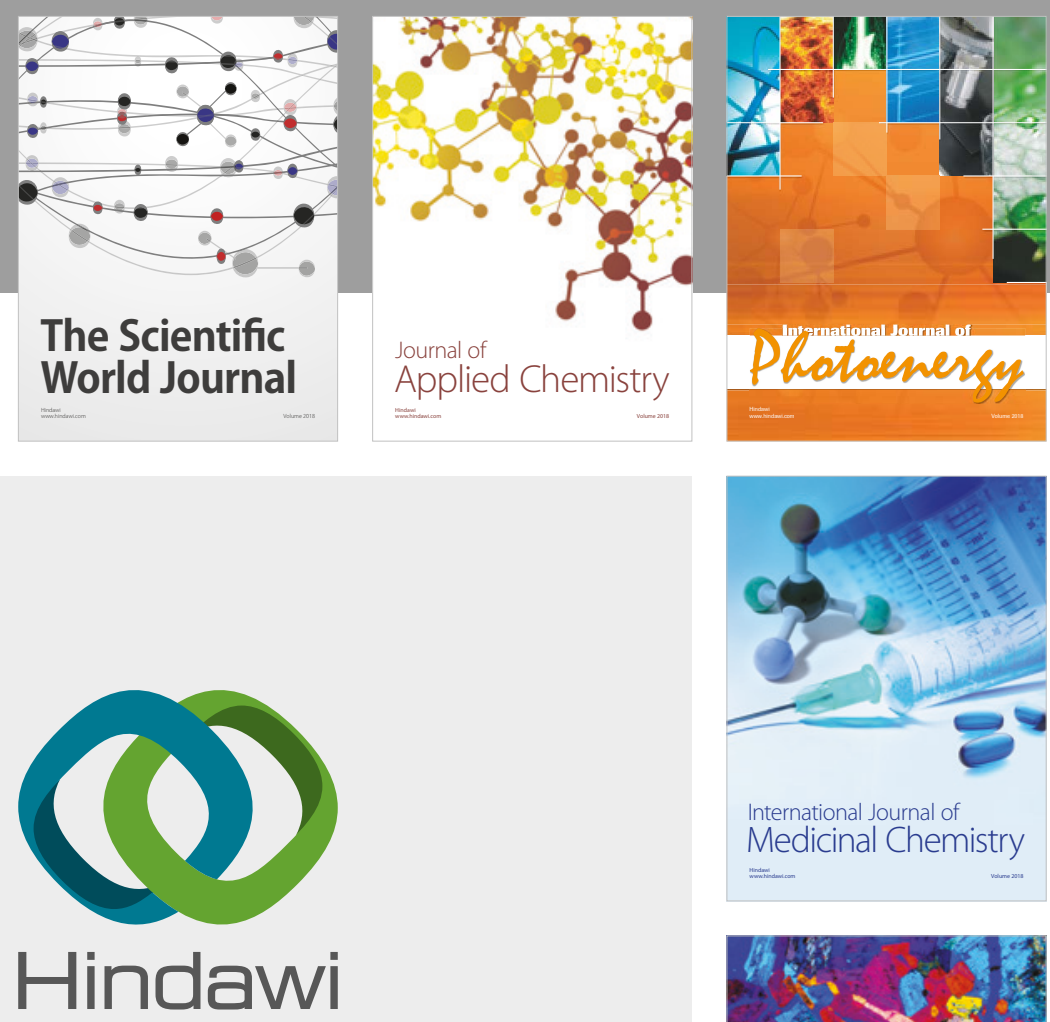

Submit your manuscripts at

www.hindawi.com
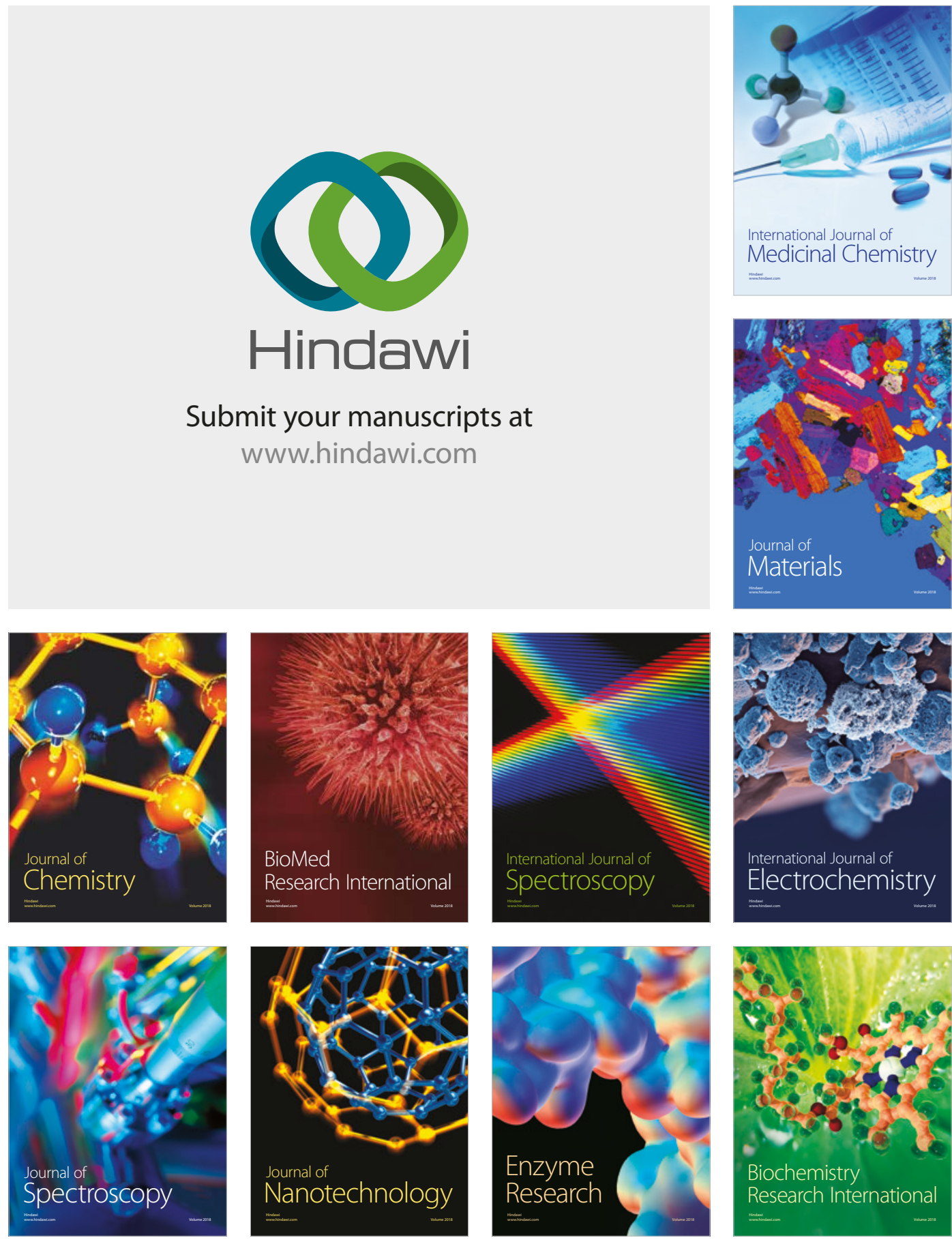
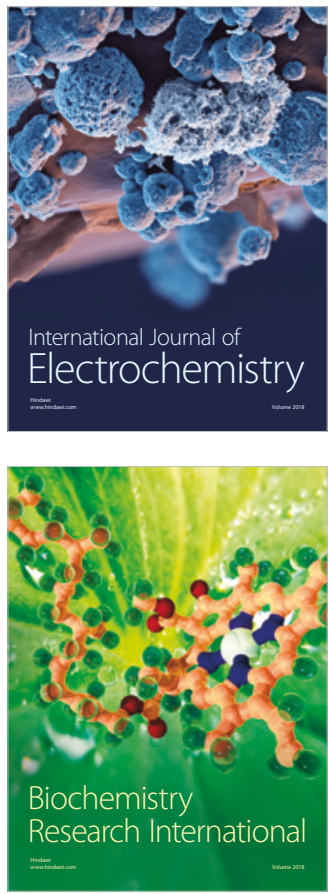